EESTI NSV TEADUSTE AKADEEMIA TOIMETISED. V KOIDE BIOLOOGILINE SEERIA: 1956, NR. 4

ИЗВЕСТИЯ АКАДЕМИИ НАУК ЭСТОНСКОИ ССР. ТОМ V СЕРИЯ БИОЛОГИЧЕСКАЯ. 1956, N 4

\title{
О ВЛИЯНИИ ДИМЕДРОЛА И ПЕНТОКСИЛА НА ТЕЧЕНИЕ НЕКОТОРЫХ ВИДОВ АСЕПТИЧЕСКИХ ВОСПАЛИТЕЛЬНЫХ РЕАКЦИЙ
}

\author{
Г. А. МИХАИЛЕЦ, \\ кандидат медицинских наук
}

В течение последних лет были достигнуты большие успехи в области изыскания и внедрения в клиническую практику антигистаминных препаратов. Клиническое применение и фармакологическое изучение димедрола, неоантергана, фенергана и др. антигистаминных препаратов показало, что помимо антигистаминного действия они оказывают существенное влияние на центральную нервную систему, обладают спазмолитическими свойствамми, понижают проницаемость сосудов, развивающуюся при воздействии различных повреждающих агентов (Вотчал и Соловьев, 1955).

По данным Гальперна (цит. по Вотчал и Соловьев, 1955), противогистаминные препараты задерживают развитие тканевого отека, вызванного гистамином, ипритом, адреналином и другими ядами.

На противовоспалительное действие антигистаминных средств указывают также работы Тимирас и Вильгельми (цит. по Вотчал и Соловьев, 1955), Доменьоса и др.

3. А. Эртуганова (1955) наблюдала благотворное влияние димедрола на течение пневмококковой инфекции у кроликов. У животных, получавших димедрол, воспалительный процесс на месте внутрикожного введения пневмококков либо совсем не развивался, либо развивался в очень незначительной степени.

В настоящей работе мы сравнили на «моделях» токсического отека легких и «формалинового» воспаления лапок у белых крыс противовоспалительное действие антигистаминного препарата димедрола и пентоксила - нового средства, стимулирующего лейкопоэз и применяющегося для лечения различных видов алейкий. Как показал И. Ф. Грех (1954), пентоксил оказывает выраженное противовоспалительное действие, уменьшая экссудативно-альтеративные явления при ожоге ушных раковин у кроликов и увеличивая степень сохранения поврежденных тканей.

\section{Влияние димедрола и пентоксила на течение токсического отека легких у белых крыс}

Токсический отек легких у крыс вызывался окислами азота в концентрациях $1 \mathrm{mr} / л$. Әкспозиция во всех опытах равнялась 30 минутам. Одновременное отравление контрольных и подопытных животных (в обе группы подбирались животные равного веса и одинакового пола) проводилось статическим методом в герметической камере, объемом в 107 литров. 
Об эффективности действия изучавшихся веществ мы судили по продолжительности жизни подопытных животных, по их выживаемости и по величине легочного коэффициента, который представляет собой отношение веса легких, выраженного в миллиграммах, к весу тела, выраженному в граммах.

В первых трех сериях опытов было изучено лечебное действие димедрола и пентоксила. Препараты в этих опытах вводились внутрь первый раз непосредственно после отравления, а затем через 3 и 9 часов после первого введения. Контрольные животные получали в те же сроки соответствующее количество воды, вводимое тем же путем.

Результаты опытов представлены в табл. 1.

Таблица 1

Влияние лечебного применения димедрола и пентоксила на продолжительность жизни белых крыс, отравленных окислами азота и на величину их легочного коэффициента

\begin{tabular}{|c|c|c|c|c|c|c|c|}
\hline \multirow{2}{*}{$\begin{array}{l}\text { Серия } \\
\text { опыта }\end{array}$} & \multirow{2}{*}{ Препарат } & \multirow{2}{*}{$\begin{array}{l}\text { Доза } \\
\text { препа- } \\
\text { рата }\end{array}$} & \multirow{2}{*}{$\begin{array}{l}\text { Количе- } \\
\text { ство жи- } \\
\text { вотных }\end{array}$} & \multicolumn{3}{|c|}{$\begin{array}{c}\text { Погибло животных } \\
\text { в течение }\end{array}$} & \multirow{2}{*}{$\begin{array}{l}\text { Средняя ве- } \\
\text { личина ле- } \\
\text { гочного ко- } \\
\text { эффициента }\end{array}$} \\
\hline & & & & $\begin{array}{c}5 \\
\text { часов }\end{array}$ & $\begin{array}{c}9 \\
\text { часов }\end{array}$ & $\begin{array}{c}24 \\
\text { часов }\end{array}$ & \\
\hline I & $\begin{array}{l}\text { Димедрол } \\
\text { Пентоксил } \\
\text { Контроль }\end{array}$ & $\begin{array}{l}0,25 \mathrm{mr} / \mathrm{r} \\
\times 3 \text { раза } \\
1 \mathrm{mr} / \mathrm{r} \\
\times \quad 3 \text { раза } \\
\quad-\end{array}$ & $\begin{array}{l}10 \\
10 \\
10 \\
\end{array}$ & $\begin{array}{r}4 \\
6 \\
3 \\
\end{array}$ & $\begin{array}{l}6 \\
8 \\
5 \\
\end{array}$ & $\begin{array}{l}8 \\
8 \\
6 \\
\end{array}$ & $\begin{array}{l}24,0 \\
22,6 \\
19,6 \\
\end{array}$ \\
\hline II & $\begin{array}{l}\text { Димедрол } \\
\text { Пентоксил } \\
\text { Контроль }\end{array}$ & $\begin{array}{l}0,1 \mathrm{Mr} / \mathrm{r} \\
\times \quad 3 \text { раза } \\
0,5 \text { мг/г } \\
\times 3 \text { раза } \\
\end{array}$ & $\begin{array}{l}15 \\
15 \\
15 \\
\end{array}$ & $\begin{array}{l}6 \\
7 \\
5 \\
\end{array}$ & $\begin{array}{l}9 \\
9 \\
7 \\
\end{array}$ & $\begin{array}{r}10 \\
12 \\
8 \\
\end{array}$ & $\begin{array}{l}21,2 \\
24,3 \\
18,4 \\
\end{array}$ \\
\hline III & $\begin{array}{l}\text { Димедрол } \\
\text { Пентоксил } \\
\text { Контроль }\end{array}$ & $\begin{array}{c}0,05 \mathrm{мr} / \mathrm{r} \\
\times 3 \mathrm{pasa} \\
0,25 \mathrm{мr} / \mathrm{r} \\
\times 3 \text { раза } \\
\end{array}$ & $\begin{array}{l}10 \\
10 \\
10\end{array}$ & $\begin{array}{l}4 \\
3 \\
2\end{array}$ & $\begin{array}{l}4 \\
5 \\
2\end{array}$ & $\begin{array}{l}5 \\
5 \\
4\end{array}$ & $\begin{array}{l}18,6 \\
18,2 \\
16,6\end{array}$ \\
\hline
\end{tabular}

Из приводимой таблицы видно, что и димедрол и пентоксил не только не оказывают выраженного терапевтического́ действия при токсическом отеке легких, а, наоборот, несколько увеличивают смертность животных и величину их легочного коэффициента.

Хорошо известно, что в развитии патологических процессов (в том числе и отека легких) большое значение имеет фактор времени и последовательность специфических и неспецифических раздражителей. Так, например, в одной из предыдущих работ (Михайлец, 1953) нами было установлено, что стрептомицин при профилактическом его приме̊нении значительно увеличивает выживаемость подопытных животных, отравленных окислами азота. Если же антибиотик вводится первый раз непосредственно после отравления белых крыс раздражающим газом, то он либо не оказывает никакого действия на исход отравления, либо, наоборот, увеличивает смертность и величину отека легких у подопытных животных. Отчетливая зависимость адреналинового отека от последовательности действия специфического и неспецифического раздражителей показана в экспериментах Г. И. Косицкого (1956). 
Поэтому в следующих опытах изучавшиеся нами вещества (димедрол и пентоксил) вводились первый раз за 2 часа до отравления животных окислами азота, а затем через 3 и 9 часов после отравления (табл. 2).

таблица 2

Влияние профилактического и лечебного применения димедрола и пентоксила на продолжительность жизни белых крыс, отравленных окислами азота, и на величину их легочного коэффициента

\begin{tabular}{|c|c|c|c|c|c|c|c|}
\hline \multirow{2}{*}{$\begin{array}{l}\text { Серия } \\
\text { опыта }\end{array}$} & \multirow{2}{*}{ Препарат } & \multirow{2}{*}{$\begin{array}{c}\text { Доза } \\
\text { препарата }\end{array}$} & \multirow{2}{*}{$\begin{array}{l}\text { Количе- } \\
\text { ство жи- } \\
\text { вотных }\end{array}$} & \multicolumn{3}{|c|}{$\begin{array}{c}\text { Погибло животных } \\
\text { в течение }\end{array}$} & \multirow{2}{*}{$\begin{array}{c}\text { Средняя } \\
\text { величнна } \\
\text { легочного } \\
\text { коэф- } \\
\text { фициента }\end{array}$} \\
\hline & & & & $\begin{array}{c}5 \\
\text { часов }\end{array}$ & $\begin{array}{c}9 \\
\text { часов }\end{array}$ & $\begin{array}{c}24 \\
\text { часов }\end{array}$ & \\
\hline IV & $\begin{array}{l}\text { Димедрол } \\
\text { Пентоксил } \\
\text { Контроль }\end{array}$ & $\begin{array}{c}0,25 \text { мг } / \Gamma \times \\
3 \text { раза } \\
1 \text { мг/г } \times \\
3 \text { раза } \\
-\end{array}$ & $\begin{array}{l}10 \\
10 \\
10 \\
\end{array}$ & $\begin{array}{l}4 \\
3 \\
4 \\
\end{array}$ & $\begin{array}{l}5 \\
4 \\
6 \\
\end{array}$ & $\begin{array}{l}7 \\
5 \\
6 \\
\end{array}$ & $\begin{array}{l}20,7 \\
18,7 \\
19,4 \\
\end{array}$ \\
\hline V & $\begin{array}{l}\text { Димедрол } \\
\text { Пентоксил } \\
\text { Контроль }\end{array}$ & $\begin{array}{rl}0,1 \mathrm{mr} / \mathrm{r} \times \\
3 & \mathrm{paza} \\
0,5 \mathrm{mr} / \mathrm{r} \times \\
3 \mathrm{paza} \\
\end{array}$ & $\begin{array}{l}10 \\
10 \\
10 \\
\end{array}$ & $\begin{array}{l}6 \\
6 \\
4 \\
\end{array}$ & $\begin{array}{l}7 \\
6 \\
6 \\
\end{array}$ & $\begin{array}{l}7 \\
8 \\
6 \\
\end{array}$ & $\begin{array}{l}22,6 \\
20,0 \\
18,4 \\
\end{array}$ \\
\hline VI & $\begin{array}{l}\text { Димедрол } \\
\text { Пентоксил } \\
\text { Контроль }\end{array}$ & $\begin{array}{c}0,05 \mathrm{мr} / \mathrm{r} \times \\
3 \mathrm{paza} \\
0,25 \mathrm{mr} / \mathrm{r} \times \\
3 \text { раза } \\
\end{array}$ & $\begin{array}{l}10 \\
10 \\
10\end{array}$ & $\begin{array}{l}5 \\
4 \\
6\end{array}$ & $\begin{array}{l}5 \\
6 \\
6\end{array}$ & $\begin{array}{l}6 \\
8 \\
8 \\
8\end{array}$ & $\begin{array}{l}17,8 \\
23,4 \\
21,7\end{array}$ \\
\hline
\end{tabular}

Как видно из таблицы, в случаях профилактического применения димедрола и пентоксила эти препараты также не оказывают благоприятного действия на исход отравления белых крыс окислами азота. Смертность подопытных и контрольных животных была почти одинаковой, не наблюдалось значительной разницы и в величине отека легких.

\section{Влияние димедрола и пентоксила на течение «формалинового» воспаления лапок у белых крыс}

Воспаление лапок у белых крыс вызывалось подкожным введением им в стопу через подошвенную поверхность 0,1 мл $2 \%$ раствора формалина. Регистрация воспаления производилась при помощи простого прибора, предложенного для этой цели Эндерсом и Гейдбринком (1955), путем погружения стопы до уровня коленного сустава в сосуд со ртутью. Изучавшиеся вещества вводились однократно: димедрол за 30 минут и пентоксил за 1 или 2 часа до инъекции раствора формалина.

Результаты опытов, представленные в табл. 3, убедительно показывают, что в противоположность токсическому отеку легких, при котором димедрол не оказывал выраженного антифлогистического действия, применение препарата в случаях «формалинового» воспаления заметно тормозит развитие отека лапок у белых крыс.

Полученные нами в отношении димедрола данные не являются противоречивыми, ибо хорошо известно, что при токсическом отеке легких далеко не все средства, обладающие противовоспалительным действием, оказывают благотворное влияние. Это лишний раз подтверждает тот факт, что токсический отек легких является своеобразной воспалитель: ной реакцией, отличающейся от других воспалительных процессов. 
Влияние различных доз димедрола и пентоксила на течение «формалинового» воспаление лапок у белых крыс

\begin{tabular}{|c|c|c|c|c|c|c|c|c|}
\hline \multirow{2}{*}{ 땔열 } & \multirow{2}{*}{ Препараты } & \multirow{2}{*}{ 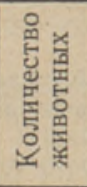 } & \multirow{2}{*}{ 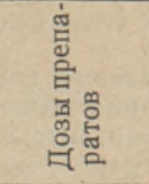 } & \multicolumn{5}{|c|}{$\begin{array}{c}\text { Средняя величина объема лапок } \\
\text { у крыс (в \%) после введення } \\
\text { формалина через }\end{array}$} \\
\hline & & & & $\begin{array}{c}30 \\
\text { минут }\end{array}$ & $\begin{array}{c}1 \\
\text { час }\end{array}$ & $\begin{array}{c}3 \\
\text { часа }\end{array}$ & $\begin{array}{c}24 \\
\text { чaca }\end{array}$ & $\begin{array}{c}48 \\
\text { часов }\end{array}$ \\
\hline I & $\begin{array}{l}\text { Димедрол } \\
\text { Димедрол } \\
\text { Контроль } \\
\end{array}$ & $\begin{array}{l}10 \\
10 \\
10 \\
\end{array}$ & $\begin{array}{c}0,25 \mathrm{Mr} / \mathrm{r} \\
0,125 \mathrm{Mr} / \mathrm{r} \\
-\end{array}$ & $\begin{array}{l}109 \\
107 \\
118 \\
\end{array}$ & $\begin{array}{l}112 \\
107 \\
121 \\
\end{array}$ & $\begin{array}{l}115 \\
110 \\
126 \\
\end{array}$ & $\begin{array}{l}118 \\
112 \\
131 \\
\end{array}$ & $\begin{array}{l}112 \\
108 \\
128 \\
\end{array}$ \\
\hline II & $\begin{array}{l}\text { Димедрол } \\
\text { Контроль }\end{array}$ & $\begin{array}{l}15 \\
15\end{array}$ & $\begin{array}{c}0,1 \mathrm{mr} / \mathrm{r} \\
-\end{array}$ & $\begin{array}{l}110 \\
116\end{array}$ & $\begin{array}{l}112 \\
119\end{array}$ & $\begin{array}{l}114 \\
122\end{array}$ & $\begin{array}{l}126 \\
136\end{array}$ & $\begin{array}{l}122 \\
130\end{array}$ \\
\hline III & $\begin{array}{l}\text { Пентоксил* } \\
\text { Пентоксил } \\
\text { Қонтроль } \\
\end{array}$ & $\begin{array}{l}15 \\
15 \\
15 \\
\end{array}$ & $\begin{array}{r}1 \mathrm{Mr} / \mathrm{r} \\
0,5 \mathrm{Mr} / \mathrm{r} \\
-\end{array}$ & $\begin{array}{l}115 \\
117 \\
119 \\
\end{array}$ & $\begin{array}{l}116 \\
121 \\
121 \\
\end{array}$ & $\begin{array}{l}119 \\
128 \\
125 \\
\end{array}$ & $\begin{array}{l}124 \\
127 \\
130 \\
\end{array}$ & $\begin{array}{l}120 \\
122 \\
124 \\
\end{array}$ \\
\hline IV & $\begin{array}{l}\text { Пентоксил } \\
\text { Пентоксил } \\
\text { Контроль }\end{array}$ & $\begin{array}{l}15 \\
15 \\
10\end{array}$ & $\begin{array}{rr}1 & \mathrm{Mr} / \mathrm{r} \\
0,5 & \mathrm{Mr} / \mathrm{r} \\
- & -\end{array}$ & $\begin{array}{l}114 \\
117 \\
115\end{array}$ & $\begin{array}{l}118 \\
119 \\
119\end{array}$ & $\begin{array}{l}122 \\
125 \\
129\end{array}$ & $\begin{array}{l}126 \\
125 \\
122\end{array}$ & $\begin{array}{l}118 \\
120 \\
116\end{array}$ \\
\hline
\end{tabular}

* В третьей серии опытов пентоксил вводился за 2 часа, а в четвертой - заं 1 час до инъекции раствора формалина.

Как видно из табл. 3, пентоксил в данном случае так же, как и в опытах с токсическим отеком легких, не оказал заметного влияния на развитие воспаления, вызванного введением раствора формалина. Отек лапок у контрольных и подопытных животных развивался приблизительно одинаково.

\section{Выводы}

1. Димедрол в дозах $0,1-0,25 \mathrm{~m} / \mathrm{\Gamma}$ не влияет на развитие токсического отека легких у белых крыс и значительно тормозит воспалительную реакцию при введении им раствора формалина.

2. Пентоксил в дозах $0,5-1$ мг/г не оказывает выраженного действия ни при токсическом отеке легких, ни при «формалиновом» воспалении лапок у белых крыс.

\section{ЛИТЕРАТУРА}

Вотчал Б. Е. и С оловье в В. Н., Противогистаминные препараты. Клиническая медицина, 1955, № 12 , стр. 3-12.

Г рех И. Ф., О противовоспалительном влиянии метацила и пентоксила. Фармакология и токсикология, 1954 , № 5, стр. 36-39.

К ос и ц и й Г. И., Значение последовательности действия раздражителей в развитии патологических процессов. (Экспериментальное исследование.) Архив патологии, 1956, № 1, стр. 15-21.

М и х айлец Г. А., Влияние стрептомицина на течение и исход токсического отека легких.- Фармакология и токсикология, 1953, № 4, стр. 33-36.

Э р туганов а 3. А., Влияние антигистаминных веществ на развитие воспалительного процесса. Журнал микробиологии, эпидемиологии и иммунологии, 1955, № 5 , стр. $90-95$.

Enders, A. und He idbrink, W., Volumetrische Messung des Rattenpfotenödems durch Verdrängung von Quecksilber. - Zeitschr. für die gesam. exp. Medizin, Bd. 126,1955 , S. $79-81$.

Ннститут өкспериментальной и клинической медицины Поступила в редакцию Академии маук Эстонской ССР

9 IV 1956 


\title{
DIMEDROOLI JA PENTOKSUULI MÕJUST MÕNEDE ASEPTILISTE PÓLETIKULISTE REAKTSIOONIDE KULGEMISELE
}

\author{
G. MIHHAILETS,
}

- meditsiiniteaduste kandidaat

\section{Resümee}

Uuriti antihistamiinse preparaadi dimedrooli ja uue leukopoeesi stimuleeriva ning mitut liiki aleukeemiate puhul rakendatava preparaadi pentoksüüli põletikuvastast toimet toksilise kopsuturse ja valgete rottide käppadel tekitatava «formaliin»-põletiku puhul. Selgus, et dimedrool annustes $0,1-0,25 \mathrm{mg} / \mathrm{g}$ ei avalda olulist môju lämmastikhapendiga tekitatud toksilise kopsuturse kulgemisele ega lõppele, pärssides aga tunduvalt valgete rottide käppadel «formaliin»-pöletikku. Pentoksüül annustes $0,5-1 \mathrm{mg} / \mathrm{g}$ ei avalda märgatavat toimet nendele patoloogilistele reaktsioonidele.

Eesti NSV Teaduste Akadeemia

Eksperimentaalse ja Kliinilise Meditsiini Instituut
Saabus toimetusse

9. IV 1956

\section{L'INFLUENCE DU DIMEDROL ET DU PENTHOXYL SUR LE COURS DE CERTAINES FORMES DE REACTION INFLAMMATOIRE ASEPTIQUE}

\section{G. MIKHAYLETZ}

\section{Résumé}

A l'aide des «modeles» de l'oedème pulmonaire toxique et d'inflammation, causée par le formol aux pattes des rats blancs, a été etudiée l'action antiphlogestique du dimedrol et du penthoxyl-nouveau médicament stimulant la production des leucocytes et qu'on emploie pour le traitement des diverses formes d'agranulocytoses. Il fut établi que le dimedrol par doses $0,1-0,25 \mathrm{mg} / \mathrm{g}$ n'influence pas le cours et l'issue de l'oedème pulmonaire toxique, causé par les oxyde de l'azote, et produit une action essentiellement inhibente sur l'inflammation, causée par le formol aux pattes des rats blancs. Le penthoxyl par doses $0,5-1,0 \mathrm{mg} / \mathrm{g}$ ne produit aucune influence essentielle sur le cours de ces réactions pathologiques. 